\title{
ЭПИДЕМИОЛОГИЧЕСКАЯ СИТУАЦИЯ
}

(C) Т. В. МЯКИШЕВА, М. А. ГУДЕНКОВ, 2012

УДК 616-002.5-036.22:312.6(470.332)»2005-2010»

\author{
T. В. Мякишева ${ }^{1}$ М. А. Гуденков ${ }^{2}$
}

\section{ЭПИДЕМИОЛОГИЧЕСКАЯ СИТУАЦИЯ И ДИНАМИКА ЛЕКАРСТВЕННОЙ УСТОЙЧИВОСТИ МИКОБАКТЕРИЙ ТУБЕРКУЛЕЗА В СМОЛЕНСКОЙ ОБЛАСТИ ЗА 2005-2010 ГГ.}

${ }^{1}$ ГБОУ ВПО Смоленская государственная медицинская академия, 214019, Смоленск, ул. Крупской, 28;

${ }^{2}$ ОГБУЗ Смоленский противотуберкулезный клинический диспансер, 214018, Смоленск, ул. Комунальная, 10

\begin{abstract}
Эпидемиологическая ситуачия по туберкулезу в Смоленской области за период с 2005 по 2010 г. оиенена как неблагоприятная и более напряженная, чем в целом по РФ. Отмечено ее ухудшение по большинству показателей в течение последних 6 лет. Установлено недостаточное выявление больных туберкулезом в учреждениях общей лечебной сети, особенно флюорографическими методами. Отмечено изменение структуры лекарственной устойчивости микобактерий туберкулеза в области, снижение монорезистентности, рост множественной лекарственной устойчивости и сохранение полирезистентности на высоком уровне.

К л юч е в ы е с ло в а : эпидемиологические показатели, выявление туберкулеза, лекарственная устойчивость микобактерий туберкулеза
\end{abstract}

T. V. Myakisheval', M. A. Gudenkov²

THE EPIDEMIOLOGICAL SITUATION AND A TREND IN THE DRUG RESISTANCE OF MYCOBACTERIUM TUBERCULOSIS IN THE SMOLENSK REGION IN 2005-2010

Smolensk State Medical Academy, 28 Krupskaya St., Smolensk 214019

Smolensk Tuberculosis Clinical Dispensary, 10 Kommunalnaya St., Smolensk 214018

The tuberculosis epidemiological situation in the Smolensk Region in 2005-2010 was appraised as poor and more tense than that in Russia as a whole. Its deterioration was noted in terms of most indicators in the past 6 years. The general healthcare network facilities were found to inadequately detect patients with tuberculosis particularly with fluorographic methods. There was a change in the pattern of drug resistance in Mycobacterium tuberculosis in the region, a decrease in monoresistance, an increase in multidrug resistance, and preservation high of polyresistance.

$\mathrm{K}$ y w o r d s : epidemiological parameters, tuberculosis detection, drug resistance in Mycobacterium tuberculosis

Первые годы XXI века характеризовались некоторой стабилизацией отдельных показателей распространенности туберкулеза и организации противотуберкулезной помощи населению в Российской Федерации. В целом же ситуация с туберкулезом продолжает оставаться весьма напряженной $[7,8]$. Поэтому актуальным является изучение этих вопросов в настоящее время не только в масштабах страны, но и в каждом отдельном регионе. Систематический анализ статистических показателей по туберкулезу имеет большое значение для оценки эпидемиологической ситуации, повышения эффективности проводимых мероприятий по профилактике, выявлению и лечению туберкулеза $[1-3,5]$. Цель работы - анализ основных количественных и качественных эпидемиологических показателей по туберкулезу в Смоленской области за 2005-2010 гг. в сравнении с РФ и динамики лекарственной устойчивости (ЛУ) возбудителя туберкулеза.

Для корреспонденции: Мякишева Татьяна Владимировна, канд. мед. наук, доц., зав. каф. фтизиопульмонологии СГМА, e-mail: tatya-myakisheva@yandex.ru

\section{Материалы и методы}

В основу настоящего исследования легли данные годовых отчетов Смоленского областного противотуберкулезного клинического диспансера за 2005-2010 гг. и статистические показатели по РФ, по данным М. В. Шиловой $[7,8]$. Нами была проведена оценка основных эпидемиологических показателей в Смоленской области в течение 6 лет в сравнении с РФ. Проведен анализ лекарственной чувствительности микобактерий туберкулеза (МБТ) по данным областной бактериологической лаборатории. Определение ЛУ МБТ проводилось методом абсолютных концентраций путем пересева на питательные среды с добавлением противотуберкулезных препаратов $[4,6]$. Статистическую обработку данных проводили с помощью программы Excel 2003 с использованием критерия Стьюдента и доверительных интервалов. Статистически значимыми различия признавались при вероятности более $95 \%(p<0,05)$.

\section{Результаты и обсуждение}

Показатель регистрируемой заболеваемости туберкулезом на 100 тыс. населения Смоленской об- 


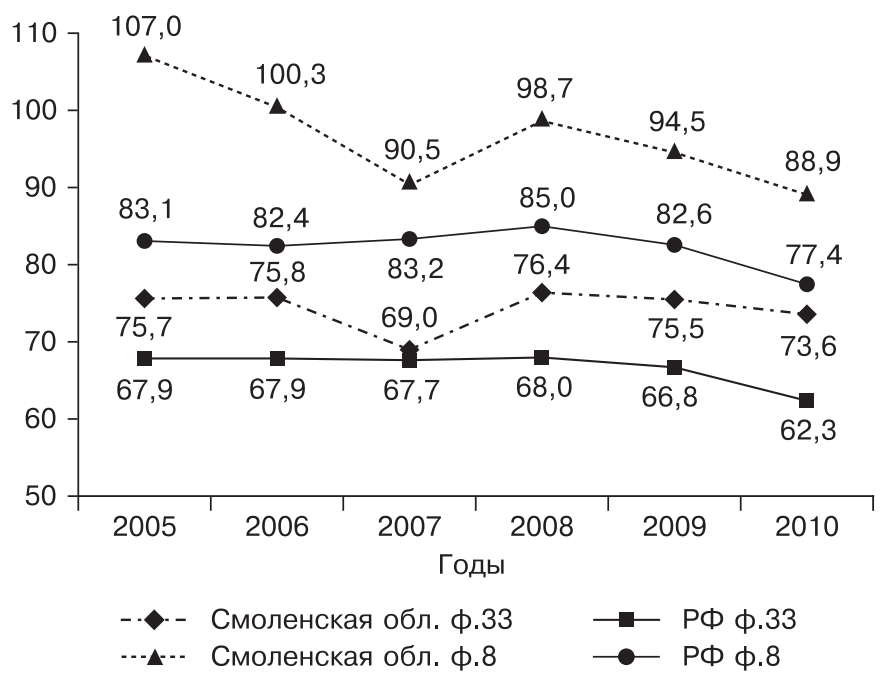

Рис. 1. Уровень заболеваемости активным туберкулезом в Смоленской области и РФ на 100000 населения (ф. 33 и 8).

ласти (ф. № 8) хотя и имел в динамике тенденцию к снижению, но достоверно превышал в течение 6 лет данный показатель по РФ (рис 1). Причем достоверность различий с РФ была высокой $(p<0,001 ; \mathrm{M} 1=$ $96,7 \pm 2,9 ;$ М2 = 82,3 \pm 0,9; ДИ1 [87,7; 105,6]; ДИ2 $[79,6 ; 85,0])$. За изучаемый период регистрируемая заболеваемость туберкулезом среди постоянного населения (ф. 33) РФ немного снизилась с 67,9 до 62,3 на 100 тыс. населения. В Смоленской области заболеваемость туберкулезом постоянного населения также уменьшилась, но менее значительно - с 75,7 до 73,6 на 100 тыс. населения, причем в 2008 г. зарегистрирован ее подъем до 76,4 в области и до 68,0 в РФ, что, возможно, связано с новым экономическим кризисом. В целом уровень данного показателя в Смоленской области достоверно превышал его значения в РФ $(p<0,001 ; \mathrm{M} 1=74,3 \pm 1,1 ; \mathrm{M} 2=66,8 \pm$ 0,8; ДИ1 [70,9; 77,7]; ДИ2 [64,2; 69,2]).

На рис. 2 представлена динамика заболеваемости туберкулезом детей от 0 до 14 лет и подростков. Показатель заболеваемости детей в Смоленской области хотя и снизился в 2010 г. в 2,2 раза с 24,3 до 11,0 , но на протяжении всего наблюдаемого периода сохранялся достоверно на более высоком уровне, чем в РФ $(p<0,005 ; \mathrm{M} 1=24,2 \pm 12,5 ; \mathrm{M} 2=16,0 \pm$ 0,$3 ;$ ДИ1 $[16,8 ; 31,6] ;$ ДИ2 [15,2; 16,9]). Что касается заболеваемости подростков, то за последние 6 лет этот показатель не превышал российский $(p<0,005$; $\mathrm{M} 1=29,1 \pm 6,0 ;$ М2 = 36,5 \pm 0,3; ДИ1 [11,0; 47,0]; ДИ2 $[35,7 ; 37,3])$ и имел тенденцию к снижению до 2008 г., но в 2010 г. он резко возрос до 54,6 на 100 тыс. подросткового населения. Таким образом, заболеваемость туберкулезом подростков в Смоленской области изменяется волнообразно, что свидетельствует о нестабильности ситуации.

Социально-экономический статус больных туберкулезом в РФ показывает преобладание неработающих $-47,6 \%$, тогда как среди населения в целом неработающие составляют только 4,3\%. Социальный состав заболевших туберкулезом в Смоленской

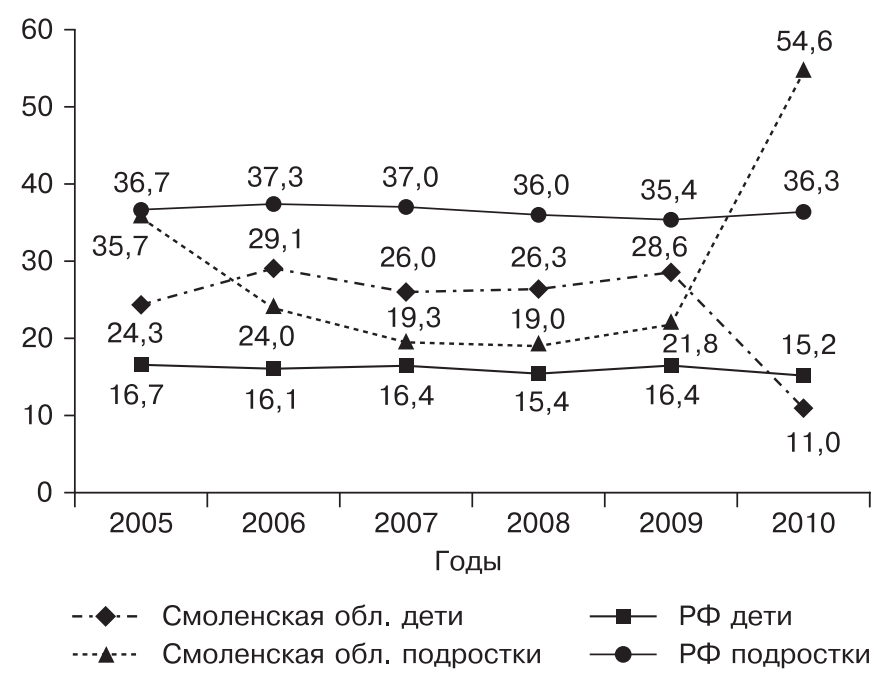

Рис. 2. Уровень заболеваемости туберкулезом детей и подростков в Смоленской области и РФ на 100000 детского и подросткового населения.

области в основном представлен лицами, не имеющими постоянной работы: в 2005 г. - 45,7\%, 2006 г. $-49,3 \%, 2007$ г. - 50,6\%, 2008 г. - 45,7\%, 2009 г. - 50,6\%, и только в 2010 г. их доля снизилась до $32,3 \%$. Таким образом, около половины впервые заболевших туберкулезом - лица с низким социальноэкономическим статусом.

Заболеваемость туберкулезом органов дыхания с бактериовыделением на 100 тыс. населения за 6 лет незначительно возросла по России с 30,9 в 2005 г. до 32,3 в 2010 г., в 2006 г. - 30,3, в 2007 г. - 29,9, с максимальным пиком в 2008 г. - 35,3 и в 2009 г. $-35,3$. В Смоленской области данный показатель незначительно снизился: в 2005 г. - 35,4, 2006 г. - 34,7, 2007 г. $-30,8,2008$ г. $-34,4,2009$ г. $-30,6,2010$ г. $-28,5$ на 100 тыс.. По Смоленской области и РФ достоверных различий показателя заболеваемости бациллярным туберкулезом не установлено $(p>0,05)$.

О своевременности выявления туберкулеза легких свидетельствуют данные об удельном весе больных с деструкцией легочной ткани. Доля фибрознокавернозного туберкулеза среди впервые выявленных больных в РФ неуклонно снижалась с 2,4\% в 2005 г. до 1,8\% в 2010 г., тогда как в Смоленской области этот показатель изменялся волнообразно с минимумом $0,9 \%$ в 2005 г. и максимумом до 2,7\% в 2007 г. В целом за 6 лет доля фиброзно-кавернозного туберкулеза в области увеличилась на $1,1 \%$ и составила в 2010 г. 2,0\%, в среднем по Смоленской области данный показатель достоверно выше, чем по РФ $(p<0,005 ; \mathrm{M} 1=4,5 \pm 2,5 ; \mathrm{M} 2=2,2 \pm 0,1 ;$ ДИ1 [-3,1; 12,1]; ДИ2 [1,8; 2,5]).

Одним из самых информативных показателей для оценки эпидемической обстановки является показатель смертности. Основной причиной смерти от инфекционных заболеваний в РФ за 2005-2010 гг. являлся туберкулез. Смертность постоянного населения от туберкулеза по РФ достигла максимального уровня в 2005 г. - 18,2 на 100 тыс. населения, что составило $88,4 \%$ всех случаев смерти от инфекци- 


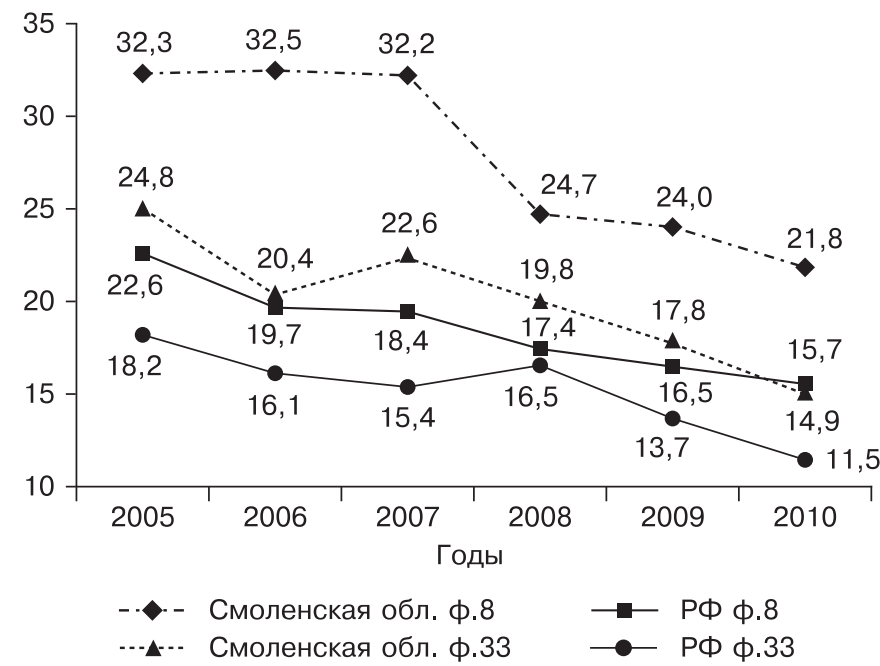

Рис. 3. Смертность населения от туберкулеза в Смоленской области и РФ на 100000 населения (формы 33 и 8).

онных заболеваний. В последующие годы зарегистрировано снижение смертности до 13,7 в 2009 г., до 11,5 в 2010 г. (рис. 3). Такая же тенденция наблюдалась в Смоленской области: в 2005 г. она достигла максимума 22,8. В 2008 г. смертность снизилась на $13,2 \%$ до 19,8, и в последующем продолжалась тенденция снижения до 14,9 на 100 тыс. в 2010 г. При сравнении данных показателей с РФ имеет место достоверное преобладание смертности постоянного населения в Смоленской области $(p<0,005$; M1 = $19,7 \pm 1,3 ; \mathrm{M} 2=15,2 \pm 1,0 ;$ ДИ1 $[15,9 ; 23,4] ;$ ДИ2 $[12,3 ; 18,2])$. Смертность по территории РФ в целом значительно снизилась на $30,5 \%$ с 22,6 на 100 тыс. населения в 2005 г. до 15,7 в 2010 г. В Смоленской области в 2005 г. данный показатель составил 32,3, в 2006г. - 32,5, в 2007г. - 32,2, далее отмечено снижение в 2008 г. до 24,7, в 2009 г. до 24,0, в 2010 г. до 21,8 . Сопоставление смертности населения по территории в Смоленской области и РФ показывает ее достоверно более высокий уровень в области ( $p<$ 0,$005 ; \mathrm{M} 1=27,1 \pm 2,5 ; \mathrm{M} 2=18,4 \pm 1,0 ;$ ДИ1 [20,5; 35,3]; ДИ2 [15,3; 21,5]).

Среди детей наиболее высокая смертность зарегистрирована в возрасте от 0 до 4 лет, особенно на 1-м году жизни. Как показывает статистика по РФ [7], именно эта возрастная категория является наиболее уязвимой вследствие внутрисемейных постоянных контактов. Максимум смертности от туберкулеза у детей в РФ отмечен в 2009 г. - 0,13, в 2008 г. - 0,06, в 2007 г. - 0,11 на 100 тыс. детского населения. За данный период в Смоленской области зарегистрирован 1 случай летального исхода в 2006 г. и 1 случай в 2010 г., в первом случае это был ребенок в возрасте до 2 лет, а во втором - 10 лет, смертность в эти годы составила 0,76 и 0,8 соответственно. В целом причинами высокой смертности от туберкулеза являются резкое увеличение тяжелых остропрогрессирующих форм заболевания, увеличение распространенности ЛУ МБТ, наличие тяжелой сопутствующей патологии почти у 70\%

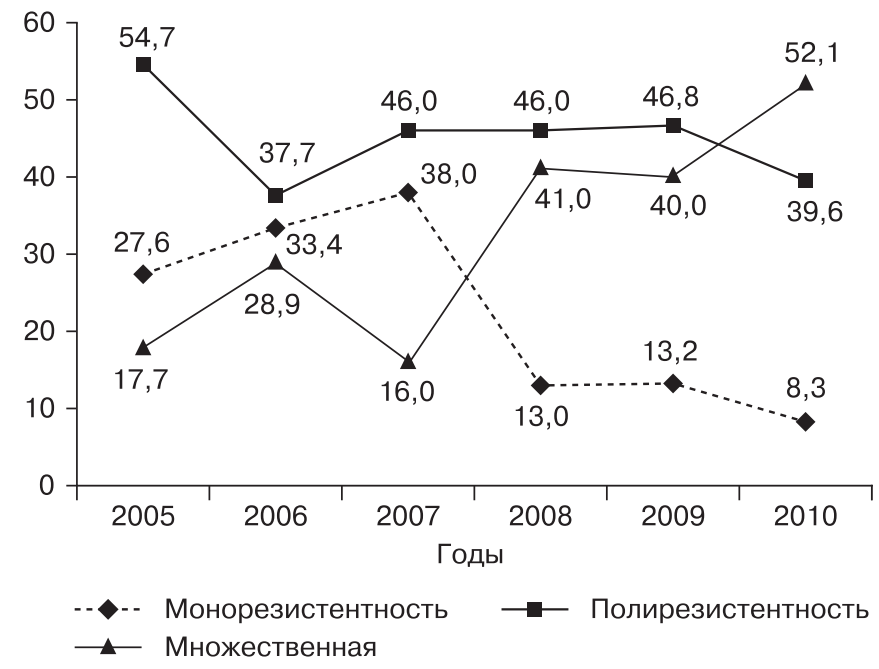

Рис. 4. Динамика структуры лекарственной резистентности МБТ в Смоленской области.

больных и отсутствие достаточного финансирования для ее лечения.

Показатели организации активного выявления больных туберкулезом во многом определяют эпидемическую обстановку. Выявление больных туберкулезом возложено на учреждения общей лечебной сети, при этом используются методы лучевой диагностики (флюорография, рентгенография), бактериоскопический, бактериологический методы исследования патологического материала и туберкулинодиагностика. Для выявления лучевыми методами в области используются 59 стационарных флюорографов, в том числе 24 (40,7\%) цифровых малодозных аппарата, 7 передвижных флюорографических установок (из них 3 (42,9\%) цифровые). С целью выявления больных туберкулезом в 2010 г. всеми методами осмотрено 76,3\%, в 2009 г. - 55,5\%, в 2008 г. - 52,5\%, в 2007 г. $-57 \%$, в 2006 г. $-54,8 \%$, в 2005 г. $-48,7 \%$, По РФ этот показатель в 2010 г. составил 63,8\%, в 2009 г. $-62,5 \%$, в 2008 г. $-61,4 \%$, в 2007 г. $-63,2 \%$, в 2006 г. $-58 \%$, в 2005 г. - 58,2\%. При оценке профилактических осмотров населения в Смоленской области в среднем установлен достоверно более низкий охват по сравнению с РФ за 6 лет $(p<0,005$; $\mathrm{M} 1=58,3 \pm 6,5 ; \mathrm{M} 2=61,2 \pm 1,2 ;$ ДИ1 [38,8; 77,8]; ДИ2 $[57,7 ; 64,6])$. Низкий охват проверочными осмотрами населения в определенной степени объясняет сохраняющуюся на высоком уровне заболеваемость туберкулезом в регионе. Рентгенофлюорографическим методом в 2005 г. было осмотрено только 36,1\% населения, в 2006 г. - 48,4\%, в 2007 г. $-39 \%$, в 2008 г. - 39,3\%. С 2009 г. наметилась тенденция к увеличению охвата профилактическими осмотрами на туберкулез лучевыми методами: в 2009 г. - 44\%, в 2010 г. - 64,7\%, что позволило повысить удельный вес больных, выявляемых при профилактических осмотрах (2009 г. - 47,2\%, 2010 г. - 45,7\%).

Для выявления первичного туберкулеза необходим максимальный охват детей и подростков туберкулиновыми пробами. Охват детского населения со- 


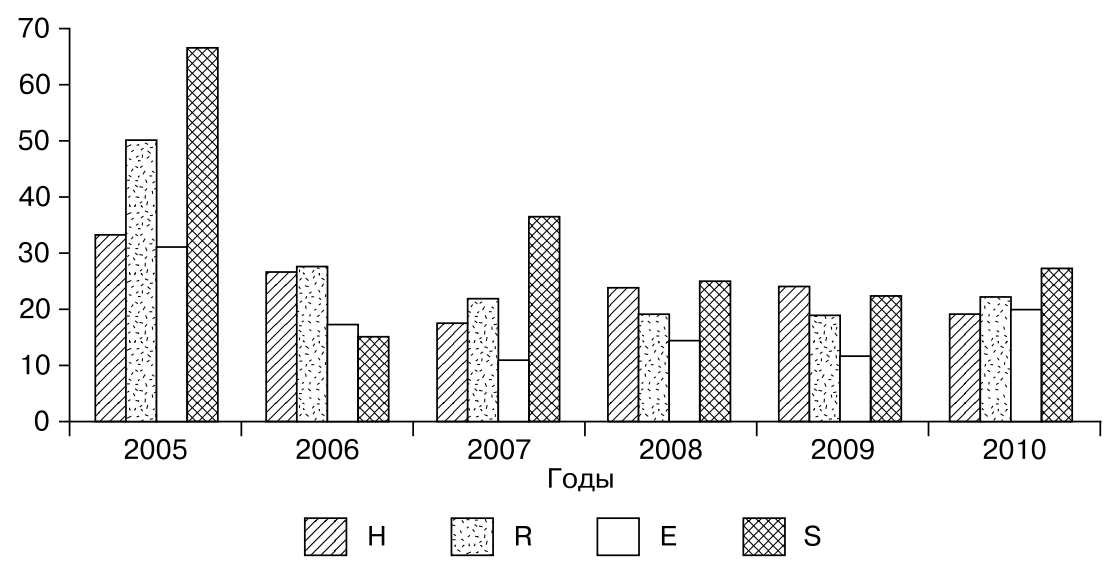

Рис. 5. Сравнительная характеристика ЛУ к препаратам первого ряда в Смоленской области.

$H$ - изониазид, $R$ - рифампицин, $E$ - этамбутол, $S$ - стрептомицин.

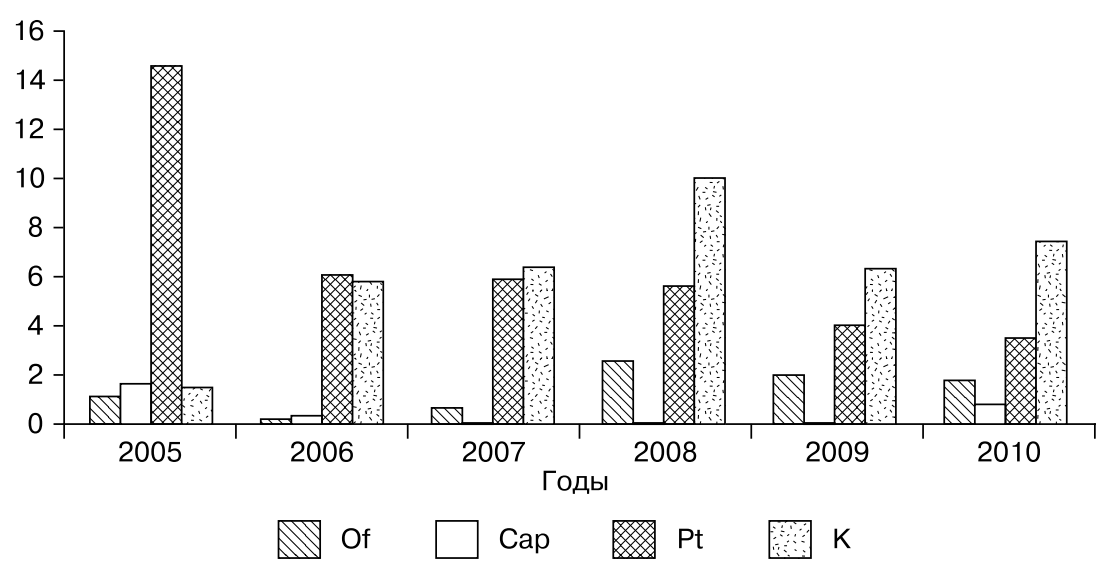

Рис. 6. Сравнительная характеристика ЛУ к препаратам второго ряда в Смоленской области. $K$ - канамицин, $P t$ - протионамид, $C a p-$ капреомицин, $O f$-офлоксацин.

ставил в 2005 г. 97,6\%, 2006 г. 95,4\%, 2007 г. 96,9\%, 2008 г. 89,6\%, 2009 г. 97,6\%, 2010 г. 98,6\%. Охват подросткового населения составил в 2005 г. 93,2\%, 2006 г. 91,4\%, 2007 г. 92,0\%, 2008 г. 82,0\%, 2009 г. 88,3\%, 2010 г. 95,0\%. Сравнительный анализ охвата туберкулинодиагностикой детей и подростков области за 6 лет показал достоверно более низкий процент охвата подросткового населения $(p<0,005 ; \mathrm{M} 1$ $=95,9 \pm 1,3 ;$ М2 $=90,3 \pm 1,9 ;$ ДИ1 [92,1; 99,8]; ДИ2 $[84,5 ; 96,1])$. Что касается профилактических флюорографических осмотров подростков, то ситуация здесь еще более сложная: охват флюорографией в 2005-2008 гг. не превышал 55,5\%, в 2009 г. составил $52,7 \%$ и только в 2010 г. увеличился до 68,2\%.

За последние 6 лет показатель распространенности туберкулеза среди жителей России значительно уменьшился с 209,7 на 100 тыс. в 2005 г. до 178,7 в 2010 г. (в 2009 г. - 185,1, 2008 г. - 190,4, 2007 г. 194,5, 2006 г. - 202,5). В Смоленской области распространенность туберкулеза менялась волнообразно: в 2005 г. - 228,7, 2006 г. - 242,1. С 2007 г. началось снижение данного показателя до 227,8, в 2008 г. - 216,9, в 2009 г. $-209,8$, а в 2010 г. $-211,0$ на 100 тыс. населения. Распространенность туберкулеза в области в среднем превышает среднероссийские показатели $(p<0,005 ; \mathrm{M} 1=222,7 \pm 5,7 ; \mathrm{M} 2=193,5 \pm 4,9 ;$ ДИ1
[205,7; 239,8]; ДИ2 [178,8; 208,2]). Распространенность фиброзно-кавернозного туберкулеза в РФ в течение изучаемого периода незначительно снижалась с 24,8 на 100 тыс. населения в 2005 г. до 22,7 в 2010 г. (2006 г. - 24,5, 2007 г. - 23,9, 2008 г. - 22,8, 2009 г. $21,9)$. Что касается распространенности данной формы туберкулеза в Смоленской области, то она менялась волнообразно и в среднем оказалась достоверно выше: в 2005 г. - 20,1, 2006 г. - 27,4, 2007 г. - 23,9, 2008 г. $-27,0,2009$ г. $-25,6,2010$ г. $-27,8$ на 100 тыс. $(p<0,05 ; \mathrm{M} 1=25,3 \pm 1,2 ; \mathrm{M} 2=23,1 \pm 0,7 ;$ ДИ1 [21,6; 28,9]; ДИ2 [20,9; 25,3]).

В настоящее время все больше внимания уделяется изучению ЛУ МБТ к противотуберкулезным препаратам (ПТП). В 2009 г. среди пациентов с туберкулезом легких в структуре преобладал инфильтративный туберкулез $(59,8 \%)$, на 2-м месте был диссеминированный $(18,4 \%), 3$-е место разделили очаговый туберкулез $(6,2 \%)$ и казеозная пневмония $(4,7 \%)$. Структура туберкулеза с ЛУ МВТ имела отличия: на 1-м месте также был инфильтративный туберкулез (48\%), но 2-е разделили фиброзно-кавернозный туберкулез (24\%) и казеозная пневмония (22\%), на 3-м месте - диссеминированный туберкулез (13\%). Следовательно, ЛУ МБТ способствует развитию распространенных прогрессирующих процессов с деструк- 
цией легочной ткани, что требует их своевременного выявления и лечения. Рассматривая структуру туберкулеза легких с ЛУ МБТ по возрастам, в течение последних 6 лет установлено, что максимальная доля приходится на возрастную категорию 35-54 года. В то же время максимальный уровень показателя заболеваемости в целом зарегистрирован в возрастной группе 25-34 года, затем идут группы 35-44 и 45-54 года $[7,8]$. Данная тенденция не случайна, так как значительный вклад наряду с первичной вносит вторичная ЛУ.

В 1999 г. в официальную государственную статистику впервые включены сведения о множественной лекарственной устойчивости (МЛУ) МБТ, т. е. устойчивости как минимум к двум препаратам: изониазиду и рифампицину. Первичная МЛУ в РФ в 2010 г. возросла по сравнению с 2005 г. на 4,9\% и составила в среднем $14,4 \%$ (в 2009 г. $-13,0 \%, 2008$ г. $-10,7 \%, 2007$ г. $-9,8 \%, 2006-9,4 \%, 2005$ г. $-9,5 \%)$ у впервые выявленных больных туберкулезом. Ее рост за этот период обусловлен как улучшением качества микробиологической диагностики, так и истинным увеличением. Динамика первичной МЛУ в Смоленской области отличалась: 2005 г. $2,8 \%, 2006$ г. - 2,8\%, 2007 г. - 0,4\%. Низкий уровень данного показателя, значительно отстающий от среднероссийского, был связан с не вполне достоверным формированием и отсутствием на тот момент картотеки бактериовыделителей в централизованной бактериологической лаборатории диспансера, а также с дефицитом чистых субстанций для определения лекарственной чувствительности. В Смоленской области в 2008 г. после налаживания работы бактериологической лаборатории первичная МЛУ зарегистрирована у 4,4\% бактериовыделителей, в 2009 г. - у 9,3\%, в 2010 г. - у 3,4\%. Среди контингентов больных МЛУ в России увеличивается: в 2005 г. $-18,7 \%, 2006$ г. - 20,3\%, 2007 г. $21,4 \%, 2008$ г. $-23,4 \%$, а в 2009 г. $-26,5 \%$ и в 2010 г. $-30,3 \%$. Данный показатель включает сведения как о первичной, так и о вторичной МЛУ. По области общая МЛУ составила в 2005 г. 6,6\%, 2006 г. $10,5 \%, 2007$ г. $8,3 \%, 2008$ г. $10,2 \%, 2009$ г. $21,8 \%$ и в 2010 г. 19,4\%. Волнообразные изменения показателя указывают на сохраняющуюся необходимость повышения качества бактериологического обследования в области.

Прослеживая структуру ЛУ МБТ в Смоленской области по годам, было отмечено увеличение монорезистентности, т. е. устойчивости к одному препарату, с 27,6\% в 2005 г. до $38 \%$ в 2007 г. и затем снижение в 2008 г. до $13 \%$, а в 2010 г. до $8,3 \%$. Одновременно наблюдался рост МЛУ, особенно значительный в 2008 г. - до 41\%, в последующем нарастание до $52,1 \%$ в 2010 г. В то же время полирезистентность, т. е. устойчивость к нескольким ПТП, кроме изониазида и рифампицина, всегда занимала большую долю в структуре ЛУ МБТ и колебалась незначительно от 37,7 до $54,7 \%$ (рис. 4). Это свидетельствует о не вполне достоверном формировании данных показателей, о разном ка- честве и объеме исследований ЛУ МБТ, а также о неэффективности применяемых стандартных схем лечения.

Для того чтобы рассмотреть влияние каждого ПТП на формирование как моно-, так и полирезистентности, мы проследили динамику ЛУ в Смоленской области к препаратам первого и второго ряда. К препаратам первого ряда относятся изониазид, рифампицин, этамбутол, стрептомицин, пиразинамид. Чувствительность к пиразинамиду в области не определялась. В целом, как и по РФ, преобладала ЛУ к стрептомицину, 2-е и 3-е место по частоте ЛУ разделили между собой рифампицин и изониазид, на 4-й позиции чаще оказывался этамбутол (рис. 5).

К препаратам второго ряда, к которым определялась чувствительность МБТ, относятся канамицин, протионамид/этионамид, капреомицин и фторхинолоны (офлоксацин) (рис. 6). Динамика ЛУ к канамицину отражает рост резистентности с $1,6 \%$ в 2005 г. до $7,6 \%$ в 2010 г., что обусловлено более частым использованием этого ПТП в последнее время в связи распространенностью ЛУ МБТ. С 2006 г. и далее зарегистрировано некоторое снижение ЛУ к протионамиду. Учитывая низкий уровень ЛУ к капреомицину и фторхинолонам, сохраняются перспективы использования этих препаратов в лечении туберкулеза с ЛУ МБТ в дальнейшем.

Таким образом, установлено неблагополучие по заболеваемости туберкулезом в Смоленской области, причины которого следующие: низкий социальноэкономический уровень; большие миграционные процессы (приграничное положение, ежегодно в миграционной службе области становятся на учет 45-50 тыс. человек); недостаточная организация обследования населения на туберкулез в общей лечебной сети (низкий охват профилактическими осмотрами всеми методами, в том числе основным рентгенофлюорографическим, низкий удельный вес выявленных при профилактических осмотрах, рост числа впервые выявленных больных с деструктивными формами туберкулеза); недостаточное финансирование противотуберкулезной службы региона, которое многие годы осуществлялось по остаточному принципу (неудовлетворительное состояние материально-технической базы; отсутствие современных методов экспресс-диагностики ЛУ МБТ; недостаточное выделение средств на лекарственное обеспечение, особенно ПТП второго ряда).

\section{Выводы}

1. Эпидемиологическая ситуация по заболеваемости туберкулезом в Смоленской области за 20052010 гг. сохранялась неблагоприятной и являлась более напряженной, чем в целом по РФ

2. Отмечена тенденция к улучшению работы по своевременному выявлению больных туберкулезом: охват профилактическими осмотрами всеми методами увеличился в 1,6 раза, в том числе рентгенофлюорографическим в 1,8 раза. 
3. Сохраняется высокий уровень заболеваемости фиброзно-кавернозным туберкулезом как среди впервые выявленных больных, так и среди контингентов.

4. Низкий процент первичной лекарственной устойчивости МБТ связан с недостаточно эффективной работой бактериологической лаборатории.

Рекомендации по улучшению работы противотуберкулезной службы в Смоленской области:

1.Следует повысить активное выявление больных туберкулезом в учреждениях общей лечебной сети с концентрацией внимания на группах риска, в первую очередь с применением малодозной цифровой флюорографии.

2. Необходимо разработать и внедрить систему мониторинга, отслеживающую ЛУ МБТ для повышения эффективности лечения больных за счет учета региональной ЛУ.

3. Требуется улучшить финансирование фтизиатрической службы, оснастить ее современной бактериологической лабораторией с экспресс-методами диагностики ЛУ МБТ.

\section{ЛИТЕРАТ УРА}

1. Медников Б. Л. Лекарственная устойчивость Mycobacterium tuberculosis // Пульмонология. - 2005. - № 2. - С. 5-8.

2. Мишин В. Ю., Чуканов В. И. и др. Химиотерапия полирезистентного туберкулеза легких // Сборник 15-го Национального конгресса по болезням органов дыхания. - М., 2005. - С. 224.

3. Мишин В. Ю. Химиотерапия туберкулеза легких // Пульмонология. -2008 . - № 3. - С. 5-13.

4. Нечаева О. Б., Скачкова Е. И. Причины и факторы формирования лекарственной устойчивости при туберкулезе легких // Пробл. туб. - 2003. - № 9. - С. 6-9.

5. Новожилова И. А. Значимость определения лекарственной устойчивости микобактерий туберкулеза для успешного лечения туберкулеза легких // Пробл. туб. и бол. легких. - 2004. - № 4. - C. 29-30.

6. Хейфеи Л. Б. Микробиологические аспекты выявления больных туберкулезом с лекарственной устойчивостью // Пробл. туб. и бол. легких. - 2004. - № 5. - С. 3-6.

7. Шилова М. В. Туберкулез в России в 2009 году. - М., 2010.

8. Шилова М. В. Эпидемическая обстановка по туберкулезу в Российской Федерации к началу 2009 г. // Туб. и бол. легких. - 2010. - № 5. - C. 14-21.

Поступила 12.10 .11

\section{Сведения об авторах:}

Гуденков Михаил Александрович, зам. главврача по диспансерной работе СПКД. 